\title{
Iatrogenic innominate arteriovenous fistula repaired with the stent-graft
}

Bo Fu, MD, Li Dong, MD, and Jian Yang, MD

From the Department of Cardiovascular Surgery, West China Hospital of Sichuan University, Chengdu, China.

Disclosures: Authors have nothing to disclose with regard to commercial support. B.F. and L.D. are equal first authors.

Received for publication Feb 23, 2014; accepted for publication Feb 25, 2014; available ahead of print April 9, 2014.

Address for reprints: Jian Yang, MD, Department of Cardiovascular Surgery, West China Hospital of Sichuan University, No. 37, Guoxue Alley, Chengdu 610041, China (E-mail: 1123100523@qq.com).

J Thorac Cardiovasc Surg 2014;148:3234-5 $0022-5223 / \$ 36.00$

Copyright (c) 2014 by The American Association for Thoracic Surgery http://dx.doi.org/10.1016/j.jtcvs.2014.02.068

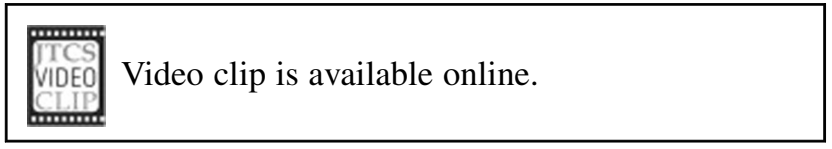

An 18-year-old man was evaluated for cardiac failure of 10 months' duration. He had undergone wiring with Kirschner wires for a left clavicle fracture 3 years previously. At that time he had no symptoms, his physical examination was
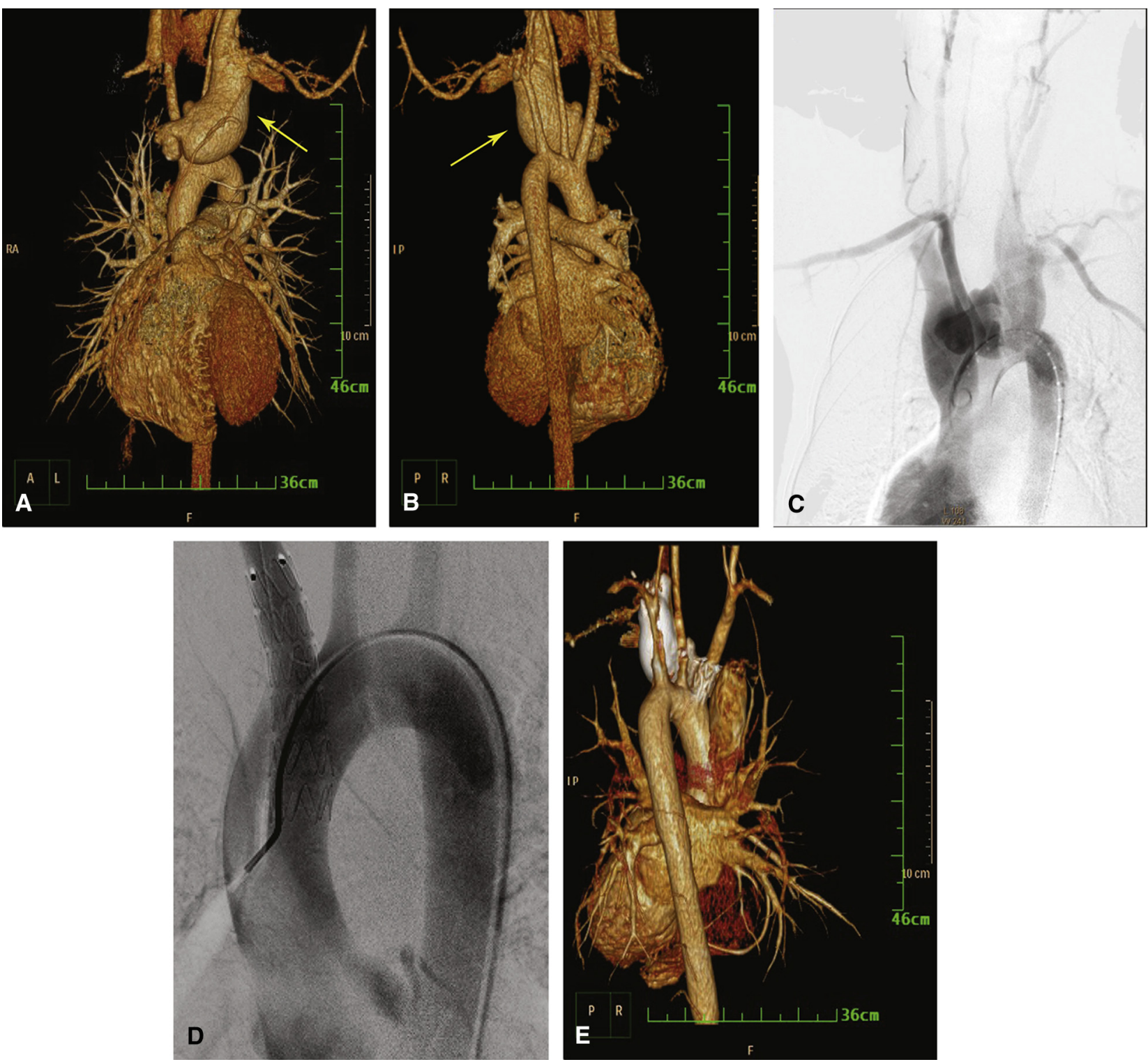

FIGURE 1. Computed tomographic scans in anterior (A) and posterior (B) views reveal a dilated left innominate vein (arrow) and tortuosity. C, Selective angiography shows the innominate vein. $\mathrm{D}$, Selective angiography (D) and computed tomography (E) show the surgical repair. 
reported as unremarkable, a chest radiograph was reported as normal, and he was discharged after 3 days.

At the index visit, the patient had a 10-month, history of dyspnea on moderate exertion with slight swelling of the neck and face. Physical examination demonstrated a continuous machinery murmur of grade IV over the entire precordium, more pronounced in the upper parasternal areas. Computed tomographic scan revealed a dilated left innominate vein and tortuosity (Figure 1, $A$ and $B$, arrow). A preoperative selective angiogram showed posterior displacement of the ascending aorta with injection into the aorta and extravasation of contrast materiel into a false aneurysm, filling the left innominate vein (Figure 1, $C$, and Video 1). Angiography finally demonstrated a fistula between the aorta (at the level of the origin of the brachiocephalic branch anteriorly) and the left innominate vein, which was identified as an innominate arteriovenous fistula. A thoracic stent graft (Medtronic Endurant; Medtronic, Inc, Watford, UK) was then implanted distal from the right common carotid artery, covering the fistula (Figure 1, $D$ and $E$, and Video 2).

Trauma-induced fistulas and pseudoaneurysms of the supra-aortic arteries are relatively rare but may result in disabling neurologic symptoms or death. Selective angiography is the criterion standard for diagnosis. Arteriovenous fistula is usually treated by surgical ligation and excision or transcatheter embolization. The minimally invasive endovascular approach may offer an alternative that avoids the tissue damage, bleeding, infectious complications, pain, disability, long recovery time, and high financial cost associated with surgery. Covered stents seem to be an effective method to seal the dissected lumen. 